\title{
Arbuscular mycorrhizal symbiosis elicits shoot proteome changes that are modified during cadmium stress alleviation in Medicago truncatula
}

\author{
Achref Aloui ${ }^{1,2 \dagger}$, Ghislaine Recorbet ${ }^{1 *}{ }^{*}$, Franck Robert ${ }^{1}$, Benoît Schoefs ${ }^{1}$, Martine Bertrand ${ }^{3}$, Céline Henry ${ }^{4}$,
} Vivienne Gianinazzi-Pearson ${ }^{1}$, Eliane Dumas-Gaudot ${ }^{1}$ and Samira Aschi-Smiti ${ }^{2}$

\begin{abstract}
Background: Arbuscular mycorrhizal (AM) fungi, which engage a mutualistic symbiosis with the roots of most plant species, have received much attention for their ability to alleviate heavy metal stress in plants, including cadmium (Cd). While the molecular bases of $\mathrm{Cd}$ tolerance displayed by mycorrhizal plants have been extensively analysed in roots, very little is known regarding the mechanisms by which legume aboveground organs can escape metal toxicity upon AM symbiosis. As a model system to address this question, we used Glomus irregularecolonised Medicago truncatula plants, which were previously shown to accumulate and tolerate heavy metal in their shoots when grown in a substrate spiked with $2 \mathrm{mg} \mathrm{Cd} \mathrm{kg}^{-1}$.

Results: The measurement of three indicators for metal phytoextraction showed that shoots of mycorrhizal $M$. truncatula plants have a capacity for extracting $\mathrm{Cd}$ that is not related to an increase in root-to-shoot translocation rate, but to a high level of allocation plasticity. When analysing the photosynthetic performance in metal-treated mycorrhizal plants relative to those only Cd-supplied, it turned out that the presence of G. irregulare partially alleviated the negative effects of $\mathrm{Cd}$ on photosynthesis. To test the mechanisms by which shoots of $\mathrm{Cd}$-treated mycorrhizal plants avoid metal toxicity, we performed a 2-DE/MALDI/TOF-based comparative proteomic analysis of the $M$. truncatula shoot responses upon mycorrhization and $\mathrm{Cd}$ exposure. Whereas the metal-responsive shoot proteins currently identified in non-mycorrhizal $M$. truncatula indicated that $\mathrm{Cd}$ impaired $\mathrm{CO}_{2}$ assimilation, the mycorrhiza-responsive shoot proteome was characterised by an increase in photosynthesis-related proteins coupled to a reduction in glugoneogenesis/glycolysis and antioxidant processes. By contrast, $\mathrm{Cd}$ was found to trigger the opposite response coupled the up-accumulation of molecular chaperones in shoot of mycorrhizal plants relative to those metal-free.

Conclusion: Besides drawing a first picture of shoot proteome modifications upon AM symbiosis and/or heavy metal stress in legume plants, the current work argues for allocation plasticity as the main driving force for $\mathrm{Cd}$ extraction in aboveground tissues of $M$. truncatula upon mycorrhization. Additionally, according to the retrieved proteomic data, we propose that shoots of mycorrhizal legume plants escape $\mathrm{Cd}$ toxicity through a metabolic shift implying the glycolysis-mediated mobilization of defence mechanisms at the expense of the photosynthesisdependent symbiotic sucrose sink.
\end{abstract}

\footnotetext{
* Correspondence: recorbet@dijon.inra.fr

+ Contributed equally

'UMR INRA 1088/CNRS 5184/UB. Plante-Microbe-Environnement. INRA-CMSE.

BP 86510. 21065 Dijon Cedex, France

Full list of author information is available at the end of the article
} 


\section{Background}

Cadmium $(\mathrm{Cd})$ is a widespread hazardous heavy metal, whose release in the plant environment has been dramatically accelerated by anthropogenic activities such as mining, refining, and soil amendments with sewage sludge and phosphate fertilizers [1]. Cd is generally harmful to most plant species in which its accumulation induces leaf chlorosis, root necrosis and decreases in growth and tissue-size [2]. The main known mechanisms of $\mathrm{Cd}$ ion $\left(\mathrm{Cd}^{2+}\right)$ toxicity in living organisms include its affinity for sulfhydryl groups in proteins and its ability to replace some essential metals in active sites of enzymes, thus causing inhibition of enzyme activities and protein denaturation $[2,3]$. Oxidative stress also belongs to $\mathrm{Cd}$-induced plant cell responses as a consequence of interference with antioxidant enzymes and depletion of antioxidant molecules [4], which may result in oxidative damages to phospholipid membranes, proteins and DNA [5,6]. Several mechanisms susceptible to counteract $\mathrm{Cd}$ toxicity have been identified in plants including active efflux and reduced transport at the plasmalemma, metal chelation by high-affinity ligands such as phytochelatins, glutathione and metallothioneins, and compartmentalization into the vacuole [7]. Besides these intracellular processes, exudates secretion, metal binding to the cell wall and rhizospheric microorganisms also have the potential to contribute to plant defence mechanisms against $\mathrm{Cd}$ toxicity $[2,8,9]$.

Notably, arbuscular mycorrhizal (AM) fungi, which engage a mutualistic symbiosis with the roots of most plant species, Arabidopsis (Brassicaceae) belonging to the noticeable exceptions, have received much attention for their ability to increase heavy metal tolerance in plants $[2,10,11]$. By enlarging the volume of soil explored by the roots thanks to an extensive extra-radical network, these ubiquitous soil borne microorganisms can increase plant phosphate, micronutrient and water uptake [12]. In turn, AM fungi that are obligate plant biotrophic microorganisms are supplied with the organic carbon forms essential for them to achieve their full life cycle [13]. Actually, a substantial amount of photosynthetically fixed carbon is channelled for synthesis of sucrose, which after cleavage represents the main source of hexoses translocated to AM fungi [14]. As a result, the sucrose symbiotic sink diverts the flow of triose phosphates produced through the Calvin cycle to feed mycorrhizal intraradical structures. Depending on the combination of host, fungus and heavy metal, phytostabilization and/or phytoextraction can contribute to alleviate metallic stress in mycorrhizal plants: in the former case, heavy metals are immobilized in the rhizosphere through precipitation in the soil matrix, adsorption onto the root surface or accumulation within roots, whereas in the latter, heavy metals are compartmentalized in plant aboveground parts through root-toshoot transfer mechanisms and/or increased biomass production [11].

Nonetheless, researches regarding shoot tolerance mechanisms upon heavy metal phytoextraction have been essentially conducted in hyperaccumulator plant species; so that there is little evidence regarding those processes by which mycorrhiza allow plant shoots to cope with metal stress [15]. Actually, probably because roots are considered as the main site of metal toxicity exposure, the cellular and molecular bases of Cd tolerance of mycorrhizal plants have been essentially grasped at the belowground level [16-22]. Although it has been demonstrated that mycorrhizal legumes can accumulate and tolerate $\mathrm{Cd}$ in their aboveground organs [11,22,23], and despite evidences for a role of plant aerial organ proteins in heavy metal stress tolerance (reviewed in [24]), large-scale data are lacking regarding the molecular mechanisms by which shoots of mycorrhizal legumes can escape $\mathrm{Cd}$ toxicity. In a previous study, we reported on the protective effect conferred by AM symbiosis to $M$. truncatula plants grown in Cd-contaminated substrate with regard to plant biomass and phytotoxicity symptoms [22]. Because mycorrhizal M. truncatula plants also were found to accumulate $\mathrm{Cd}$ in their shoots, we choose this system as a model to investigate the mechanisms by which legume shoots tolerate $\mathrm{Cd}$ toxicity upon AM symbiosis. In the present work, to complement the physiological parameters that were measured to obtain structural and functional information on the impact of $\mathrm{Cd}$ and/or mycorrhization on plant biomass and photosynthetic activity, a two-dimensional electrophoresis (2-DE)-based study was further used to compare $M$. truncatula shoot responsive proteins upon AM colonization and Cd application. We report on a first picture of plant legume shoot proteome modifications displayed upon AM symbiosis and their modulation in response to Cd stress, which allowed proposing a working model to explain heavy metal tolerance in aboveground organs of legume mycorrhizal plants.

\section{Results and Discussion}

Shoots of mycorrhizal $M$. truncatula plants have a capacity for extracting $\mathrm{Cd}$, which is not related to an increase in root-to-shoot translocation rate but to allocation plasticity

To go further in analysing the tolerance to $\mathrm{Cd}$ displayed by $M$. truncatula when colonised by the AM fungus Glomus irregulare [22], we have investigated in the current study the potential contribution of mycorrhizal plants to phytoextraction, which refers to the transfer of 
inorganic contaminants from soil to harvestable aboveground plant tissues [25]. Because phytoextraction relies on the capacity of plants to accumulate and tolerate heavy metals in their shoots, its efficiency depends both on the ability of metal to be translocated in aerial plant organs and on shoot biomass production [25-27]. To take into account biomass production, which actually escapes indices calculated on the basis of $\mathrm{Cd}$ concentration $[27,28]$, three main indicators have been used to measure plant effectiveness in extracting $\mathrm{Cd}$ from soil: the tolerance index expressed as the ratio of shoot growth parameters for plants grown in polluted soil to plants grown in metal-free soil $[26,27,29]$, the transport factor calculated as the ratio of the total $\mathrm{Cd}$ amount in shoots to that in roots $[27,30]$, and Cd partitioning that corresponds to the metal quantity present in plant organs [28]. When calculated for M. truncatula plants grown for three weeks in Cd-spiked substrate $\left(2 \mathrm{mg} \mathrm{kg}^{-1}\right)$ in the presence or not of G. irregulare, the first indicator showed that mycorrhizal plants displayed a reproducible and significant increase in shoot tolerance to $\mathrm{Cd}$ relative to those non-mycorrhizal (Figure 1A), a result corroborating a previously reported enhanced $M$. truncatula aboveground biomass in $\mathrm{Cd}$-contaminated soils when inoculated with G. irregulare [28]. Concomitantly, although the root-to-shoot translocation rate of $\mathrm{Cd}$ was

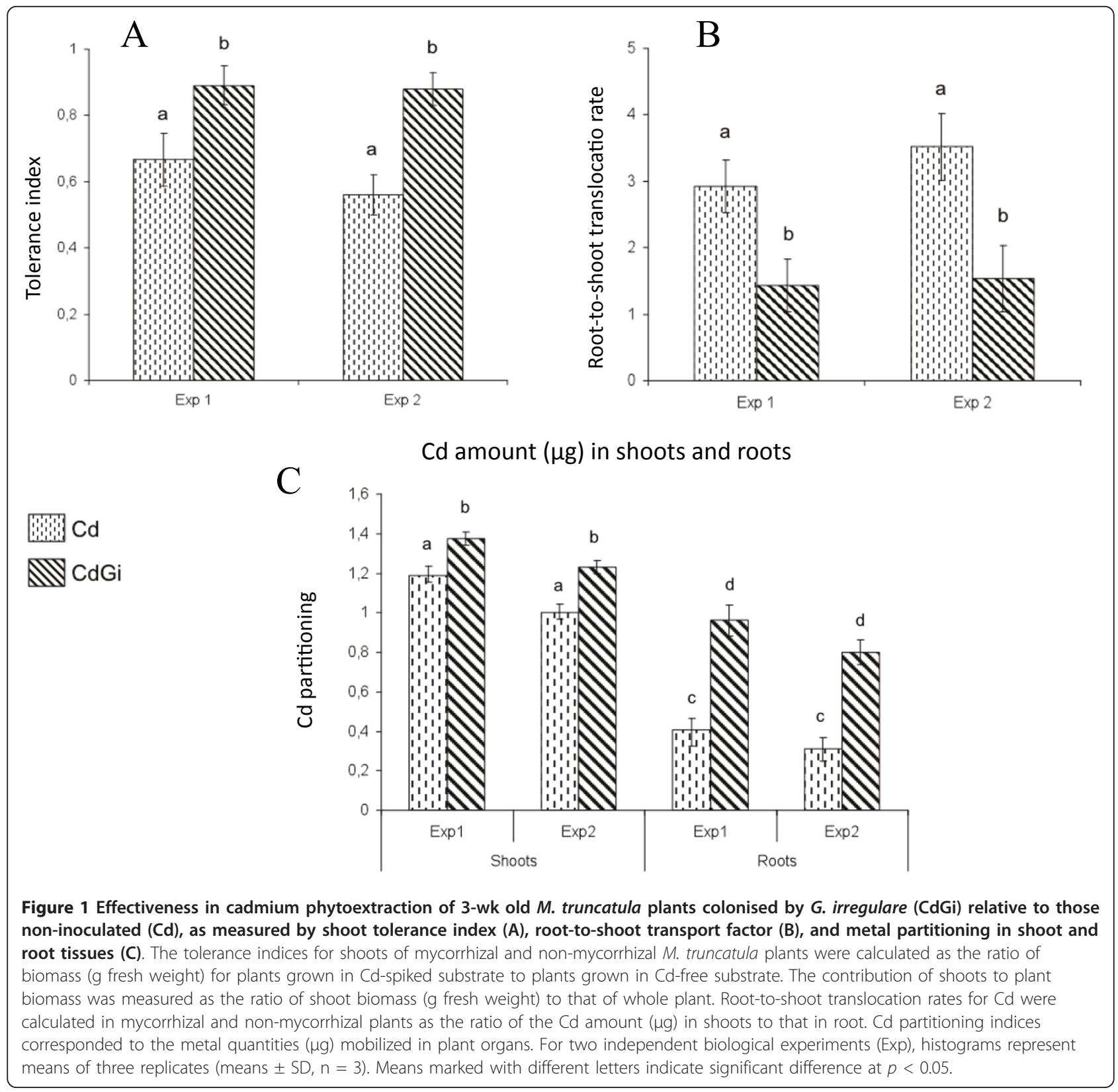


significantly reduced by two-fold in G. irregulare-colonised plants compared to those non-inoculated (Figure 1B), reflecting the important role of mycorrhizal roots in heavy metal sequestration [22], Cd partition patterns (Figure 1C) indicated that shoots of mycorrhizal plants contained the highest metal quantity relative to shoots of non mycorrhizal plants and $M$. truncatula roots, either G. irregulare-colonised or not. From these three indicators for metal phytoextraction, it could be concluded that shoots of mycorrhizal $M$. truncatula plants have a capacity for extracting $\mathrm{Cd}$, which is not related to an increase in root-to-shoot transport factor, a result previously observed in Cd-treated mycorrhizal sunflowers plants [31]. As a strategy for metal phytoextraction alternative to increase in root-to-shoot transfer mechanisms, it has been proposed that a significant shift in root-to-shoot biomass partitioning permitted some plants to reduce the incidence of metal-induced stress in photosynthetic organs, a process referred to as allocation plasticity [32]. At the same time, an increased tolerance to metal of the photosynthetic system would allow plants maintaining high transpiration efficiency, thus creating a water flux that can drive metals from the roots into the stem and leaves where the metal can be compartmentalized [33]. To test whether this model appropriated to Cd-treated mycorrhizal M. truncatula plants, we thus compared between treatments the biomass allocation pattern and the chlorophyll (Chl) content as an indicator of metal-induced damage to the photosynthetic apparatus. With regard to root-to-shoot partition in M. truncatula plants upon Cd exposure and/or mycorrhizal infection (Figure 2A, Additional file 1 ), it happened that whereas $\mathrm{Cd}$ application reduced the biomass allocated to the shoots in non-mycorrhizal plants relative to control, mycorrhization led to its significant increase both in the absence and presence of metal. Further measurements indicated that $\mathrm{Cd}$-induced decrease in root-to-shoot biomass allocation in nonmycorrhizal plants accounted for a significant reduction both in shoot branching and leaf area per plant (Figure 2B-C). On the contrary, G. irregulare induced relative to non-mycorrhizal plants significant increases in shoot branching and leaf area, which were not significantly affected by $\mathrm{Cd}$ treatment (Figure 2B-C). In Trifolium repens, a higher leaf area in response to mycorrhization has been shown to maximize the area available for $\mathrm{CO}_{2}$ assimilation per unit of carbon invested, and thus the rate of photosynthesis [34]. In the current study, although none of the Cd-treated plants, either mycorrhizal or not, exhibited a yellowing symptom indicative of leaf chlorosis usually associated with $\mathrm{Cd}$ induceddamage (Figure 3A), significant differences in Chl content between treatments could be reproducibly recorded in plant shoots. As shown in Figure 3B, Cd led to a significant reduction in the contents of Chl $a$ and $b$ in non-mycorrhizal plants, which has been ascribed for example to the inhibition of aminolevulinic acid synthesis and protochlorophyllide photoreduction [35,36]. By contrast, a roughly two-fold increase in Chl contents was measured upon AM colonisation of the root system relative to control plants, which was not significantly affected in the presence of $\mathrm{Cd}$.

To determine whether the modifications in the Chl amount reported in Figure 3 impacted the photosynthetic activity, photosynthetic efficiencies, vitality indices, and the relative electron transport rate (ETR) were measured $[37,38]$. As presented in Figure 4 and additional file 2 for related statistics, the performance index for energy conservation from photons absorbed by PSII to the reduction of PSI end acceptors $\left(\mathrm{PI}_{\mathrm{TOT}}\right)$, and for energy conservation from photons absorbed by PSII to the reduction of intersystem electron acceptors, expressed per reaction centre $\left(\mathrm{PI}_{\mathrm{ABS}}\right)$ or per leaf cross section $\left(\mathrm{PI}_{\mathrm{CS}}\right)$ were decreased by approximately $50 \%$ in response to $\mathrm{Cd}$ in non mycorrhizal plants (Figure $4 \mathrm{~A}$ ). A decrease of $\mathrm{PI}_{\mathrm{ABS}}$ was also reported to occur in pea leaves upon Cd-treatment [26]. After calculation of the energy flux ratios, panel $\mathrm{B}$ of Figure 4 showed that the presence of $\mathrm{Cd}$ in non-mycorrhizal plants reduced significantly the maximum quantum yield of photosystem $2\left(\mathrm{~F}_{\mathrm{V}} / \mathrm{F}_{\mathrm{M}}\right.$ or $\left.\phi_{\mathrm{Po}}\right)$ relative to controls. Accordingly, quantum yield for electron transport $\left(\phi_{\mathrm{Eo}}\right)$ and the probability that an electron moves further than $\mathrm{Q}_{\mathrm{A}}{ }^{-}\left(\psi_{0}\right)$ were reduced in metal-treated non-mycorrhizal plants when compared to control samples (Figure 4D). Consequently, the maximum quantum yield of the non-photochemical deexcitation $\left(\phi_{\text {Do }}\right)$ increased significantly in the presence of Cd (Figure 4B). These results are in line with those obtained with other photosynthetic organisms and higher $\mathrm{Cd}$ concentrations [39]. Additionally, Figure 4C also showed that both the rate and the saturation of the light photosynthetic performance were lower in Cd-treated plants compared to controls, thus indicating that the capacity of the antenna to harvest photons is influenced by the $\mathrm{Cd}$-induced modifications in the Chl content (Figure 3). Altogether these data show that the reason for the reduced growth of Cd-treated non-mycorrhizal plants resides partly in an altered functioning of photosynthesis but also in the lowering of the density of RC. Contrasting with the effects of $\mathrm{Cd}$, the presence of $\mathrm{G}$. irregulare in metal-free plants relative to controls promotes the development of the photosynthetic apparatus as shown by the increase in the vitality indices $\mathrm{PI}_{\mathrm{ABS}}$, $\mathrm{PI}_{\mathrm{CS}}$ (Figure 4A) and relative ETR (Figure $4 \mathrm{C}$ ). The $\mathrm{PI}_{\mathrm{ABS}}$ and $\mathrm{PI}_{\mathrm{CS}}$ increases are due to the significant augmentation of the density of RCs per Chl (RC/ABS) whereas the other factors composing this vitality index were quantitatively less impacted by the presence of the 


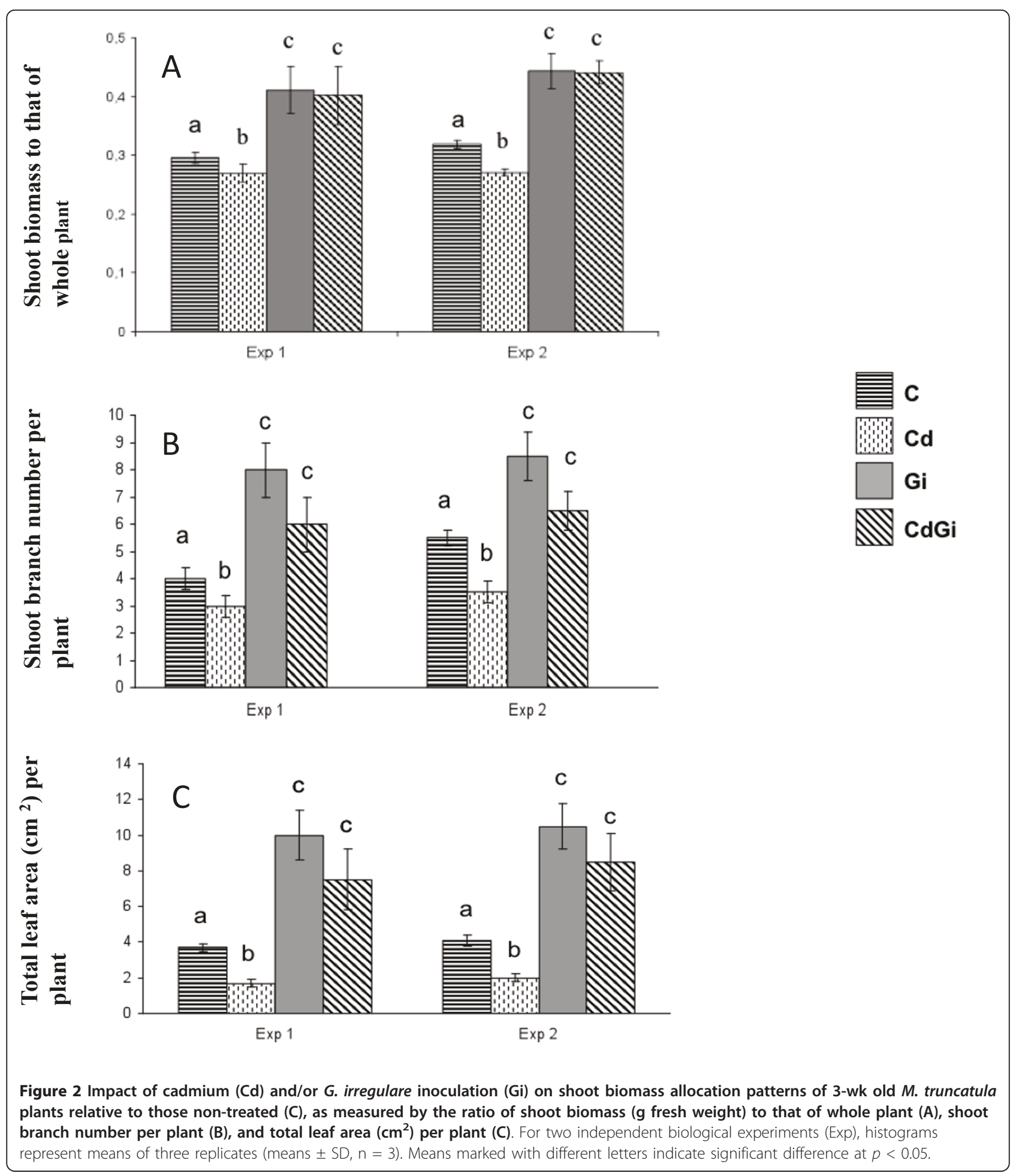

mycorrhizal fungus (Figure 4A). The photosynthetic capacity of mycorrhizal plants also is enhanced relative to controls as shown by the significant higher maximum quantum yield of photosystem $2\left(\mathrm{~F}_{\mathrm{V}} / \mathrm{F}_{\mathrm{M}}\right)$, the probability that an electron moves further than $\mathrm{Q}_{\mathrm{A}}{ }^{-}\left(\psi_{0}\right)$ and the quantum yield for electron transport $\left(\phi_{\mathrm{Eo}}\right)$, and the lower level of the quantum yield of the nonphotochemical deexcitation $\left(\phi_{\text {Do }}\right)$ (Figure $\left.4 \mathrm{~B}\right)$. Overall, the results show that the presence of the arbuscular fungus promotes photosynthesis by increasing the plant ability to use light energy, facilitating the electron transport and by increasing the density of photosynthetic units. 


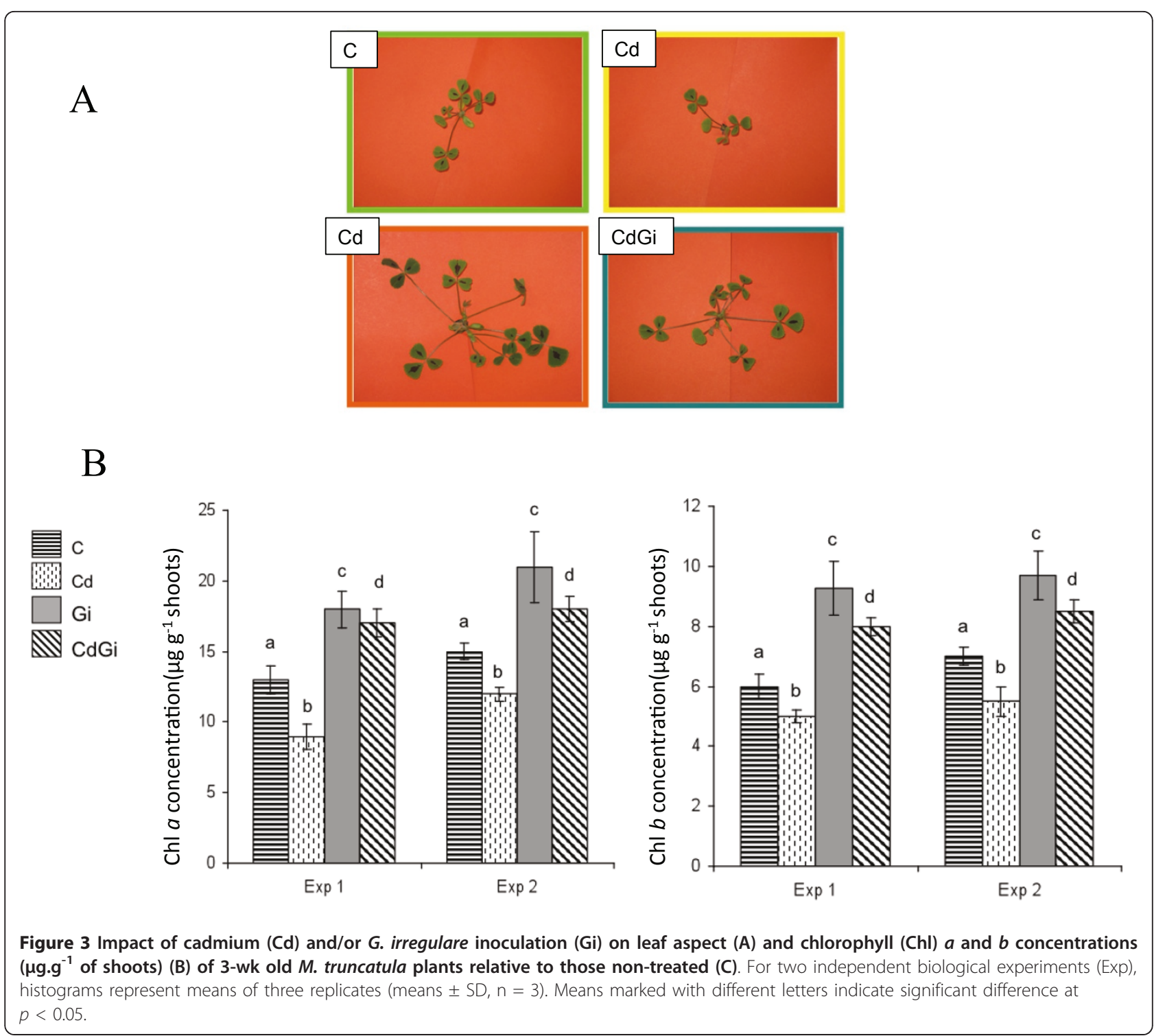

Noteworthy, when analysing the photosynthetic performance in metal-treated mycorrhizal plants relative to those only Cd-supplied (CdGi versus $\mathrm{Cd}$ ), it turned out that the presence of $G$. irregulare partially alleviated the negative effects of $\mathrm{Cd}$ on photosynthesis. Actually, the vitality indices $\mathrm{PI}_{\mathrm{ABS}}$ and $\mathrm{PI}_{\mathrm{CS}}$ (Figure $4 \mathrm{~A}$ ) and relative ETR (Figure 4C) were significantly higher in Cd-treated mycorrhizal plants relative to those only Cd-supplied. An enhanced photosynthetic capacity of Cd-treated mycorrhizal plants compared to those only $\mathrm{Cd}$-amended also is mirrored in panel $\mathrm{B}$ of Figure 4 by a significant higher value for parameters $\left(\mathrm{F}_{\mathrm{V}} / \mathrm{F}_{\mathrm{M}}\right),(\psi 0)$ and $\left(\phi_{\mathrm{EO}}\right)$ and a significant lower level for $\left(\phi_{\mathrm{Do}}\right)$.

Taken together, both biomass partitioning- and photosynthesis-related indicators support the idea that mycorrhizal M. truncatula plants extract and tolerate $\mathrm{Cd}$ by displaying a high level of allocation plasticity. According to this model, it is also assumed that metal-treated mycorrhizotrophic plants don't invest in an intrinsic tolerance mechanism typical of $A$. thaliana, which involves for example phytochelatin production [29]. To investigate this hypothesis, we have performed a 2-DE-based proteomic comparative analysis of the $M$. truncatula shoot responses upon mycorrhization and $\mathrm{Cd}$ exposure, a strategy that was proved successful to unravel and discriminate the mechanisms of metal toxicity/tolerance in different plant species and/or organs [24]. Following separation of phenol-extracted shoot proteins on 2-DE gels and Coomassie Brilliant Blue-staining, protein patterns were analysed using Progenesis workstation, resulting in the detection of 500 distinct spots displayed on a virtual reference 2-DE map (data not shown). After 

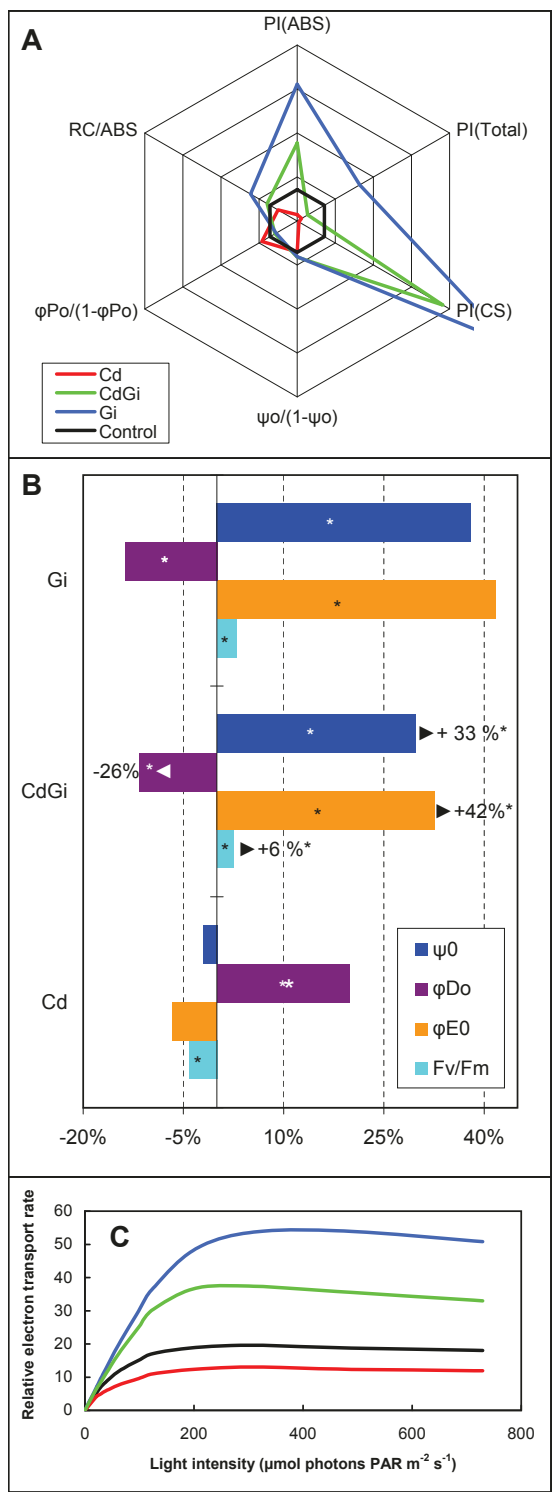

Figure 4 Influence of cadmium (Cd) and/or G. irregulare inoculation (Gi) on the parameters of the OJIP-test and relative electron transport rate. (A), Variations of performance indices and structural OJIP-test parameters plotted (spiderplot center $=0.5$, maximum $=4$ ) relative to their respective control (set as reference ticked line $\mathbf{1}$ 1). $(\mathbf{B})$, Deviation of the fluxes as expressed relative to non-treated plants. Asterisks indicate significant difference at $p<$ 0.05 . The values indicated by arrows, expressed in percents, reflect the deviation flux differences between Cd-treated mycorrhizal plants and those only $\mathrm{Cd}$-treated. Asterisks indicate significant difference at $p<0.05$. Data relative to panels A and B represent an average of 5 to 6 independent measurements. The corresponding statistical data $(n \geq 5)$ are provided in additional file 2. (C), Plot of relative of relative linear electron transport rate (ETR) as a function of quantum flux density of the photosynthetically active radiation (PAR). The ETR was measured via the fluorescence parameter (as described in Methods) in attached leaves. Data represent an average of six plant replicates. The colour legend of panel $\mathrm{C}$ is the same as for panel $\mathrm{A}$. Statistical data $(n=6)$ are provided in additional file 2 for the maximum apparent ETR (ETR MAX). using SameSpots and post-hoc statistical tests, 46 proteins, displayed on Figure 5, showed a significant $(p<$ $0.05)$ change in abundance in treated plants relative to controls, which were reproducible in the two independent biological experiments performed in the current study, each encompassing three replicates of the four treatments. Comparison of shoot responsive proteins between the three treatments revealed that the 46 significant modifications encompassed 23 distinct spots by reason of overlapping changes (Figure 6). Subsequent MALDI-TOF analyses allowed retrieving confident positive hits for all the 23 proteins of interest, and, with the exception of spot 23, all had known or homologyinferred functions (Additional files 3 and 4). When comparing, on the basis of GENESIS clustering, the groups of proteins that responded to $\mathrm{Cd}$ treatment (Cd), G. irregulare inoculation (Gi), and $\mathrm{Cd}$ treatment in mycorrhizal plants (CdGi) relative to non-treated plants (C), Figure 6 showed that G. irregulare elicited shoot protein modifications opposite to those induced by $\mathrm{Cd}$ in non-mycorrhizal plants, but also that the G. irregulare-responsive shoot proteome was qualitatively conserved but quantitatively modified upon $\mathrm{Cd}$ exposure (Figure 6).

\section{G. irregulare elicits shoot proteome changes opposite to those induced by $\mathrm{Cd}$}

Although transcript profiling performed in plant shoots has previously indicated the systemic induction of many plant genes upon mycorrhization [40], the current study allowed demonstrating that a mycorrhiza-responsive shoot proteome also exists in M. truncatula. Namely, in the absence of $\mathrm{Cd}, 21$ proteins were reproducibly detected as being significantly differentially accumulated in the shoots of mycorrhizal plants relative to those grown in the absence of G. irregulare (Figure 5B, Figure 6: column $\mathrm{Gi} / \mathrm{C})$. Among those displaying a higher abundance upon mycorrhization, were proteins having role in assimilation of $\mathrm{CO}_{2}(\mathrm{~s} 5, \mathrm{~s} 17, \mathrm{~s} 15, \mathrm{~s} 16)$, or belonging to photosystem I (s1, s2), and photosystem II (s3, s4), which sustains the view [34] of an increased photosynthetic activity in response to AM fungi. As obligate biotrophs, AM fungi receive their entire carbon requirements from a 4 to $30 \%$ proportion of plant photoassimilates [41], and consequently, photosynthetic activity is optimised for symbiosis demand [42]. This is mirrored by the increased abundance in mycorrhizal plants of proteins having role in cellular division (cyclin (s10)) and protein synthesis (RNA-binding precuror (s14)) that can help in sustaining shoot and leaf growth. Conversely, chaperonins 21 and DnaK (s12, s13), which protect newly synthesized or stress-denatured polypeptides from misfolding and aggregation [43], were up accumulated in response to symbiosis. We also noticed a reduced abundance in shoots of mycorrhizal plants of the 


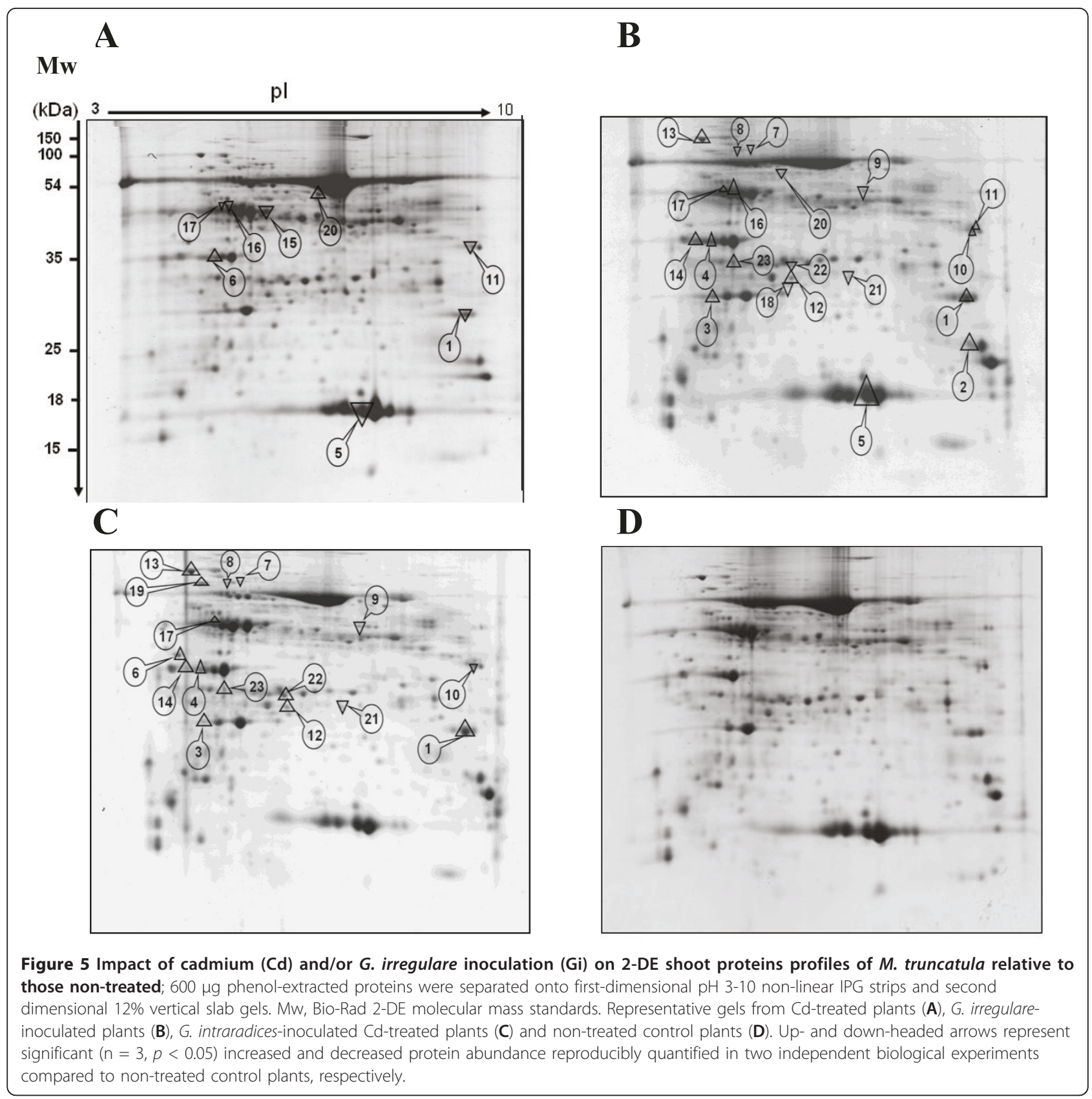

gluconeogenesis/glycolysis-related proteins phosphoglycerate mutases $(\mathrm{s} 7, \mathrm{~s} 8)$ and fructose-biphosphate aldolase (s9), which operate downstream of phosphofructokinase during glycolysis (Figure 5B, Figure 6). These results corroborate the known regulation mechanism of the Calvin cycle, which is prevented from functioning in a futile reaction through a reduction in glucose breakdown via a decreased glycolysis, a process that is achieved by the light-driven electron flow production of reduced thioredoxin, which inhibits the glycolytic enzyme phosphofructokinase $[44,45]$. Upon mycorrhization, we additionally observed in
M. truncatula shoots the up-accumulation of a mitochondrial voltage-dependent anion channel (VDAC, s11), for which reduction in abundance is regarded as a marker of oxidative damage $[46,47]$, coupled to the down-accumulation of four proteins having role in counteracting oxidative stress $(2,4 \mathrm{D}$ inducible glutathione transferase (s21), S-adenosylmethionine synthetase (s20), DHA reductase class glutathione transferase (s18), ascorbate peroxidase (s22)), which indicated a decreased need in mechanisms scavenging reactive oxygen species (ROS) in mycorrhizal plants. Actually, nonenzymatic antioxidants include the major cellular redox 


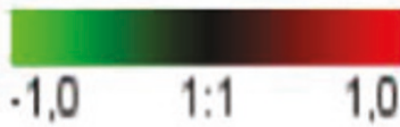

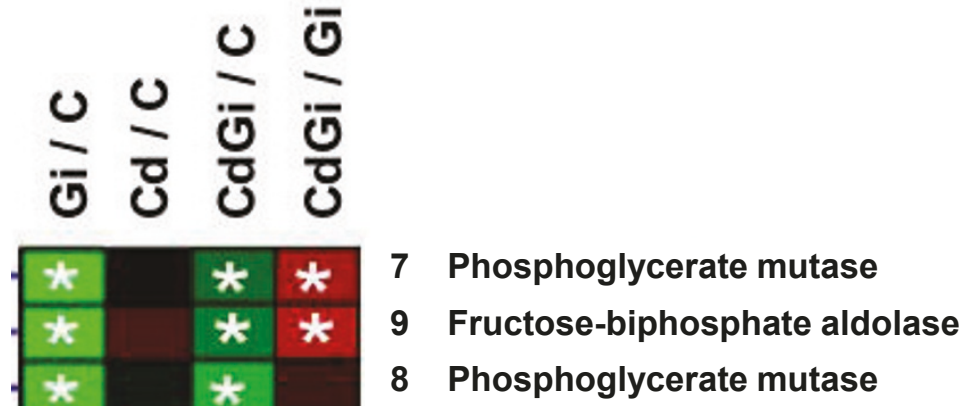

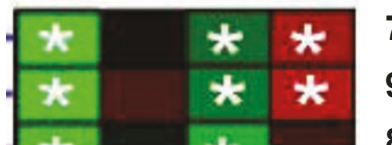

21 2,4-D inducible glutathione S-transferase

6 Glucan endo-1,3-beta-D-glucosidase

20 S-adenosylmethionine synthetase

18 DHA reductase class glutathione transferase

22 Ascorbate peroxidase

1 Photosystem I protein PsaD

14 RNA-binding protein

12 Chaperonin 21

13 Chaperone DnaK

17 RuBisCO small subunit 3A

19 Protein disulfide isomerase precursor

10 Cyclin

5 RuBisCO small subunit

11 VDAC1.1

15 RuBisCo activase

16 RuBisCO activase 1

2 Photosystem I reaction centre subunit IV/PsaE

4 Photosystem II polypeptide manganese-stabilizing protein

3 Probable protein 2 precursor OEE2

\section{Chloroplast precursor}

Figure 6 Comparison of the groups of protein spots that responded to G. irregulare inoculation and/or cadmium treatment in 3-w old M. truncatula shoots. Clustered abundance pattern using GENESIS software of the 23 shoot proteins of $M$. truncatula reproducibly detected as differentially accumulated $(n=3)$ in two independent biological experiments in response to one or both treatments. Log2 expression ratios were calculated for the different treatments $(\mathrm{Cd}, \mathrm{Gi}$ and $\mathrm{CdGi}$ ) either relative to the control reference $(\mathrm{C})$ or to $\mathrm{G}$. irregulare-inoculated plants (Gi). The green colour ( -1$)$ indicates the highest down-accumulation and the red colour (+1) the highest up-accumulation. Dark boxes (0) indicate no changes in protein abundance compared to control condition. Each row of coloured boxes is representative of a single protein and each ratio per treatment is represented using a single column, Gi/C: $\mathrm{G}$ intraradices-inoculated compared to control, Cd/C: Cd-treated compared to control, $\mathrm{CdGi} / \mathrm{C}: \mathrm{G}$ irregulare-inoculated and Cd-treated compared to control and CdGi/Gi: Cd treated and G. irregulare-inoculated compared to $\mathrm{G}$. irregulare-inoculated plants. Asterisks indicate significant differences $(p<0.05)$. Protein spots are numbered according to Figure 5. 
buffers ascorbate and glutathione (GSH). Whereas GSH is oxidized by ROS to form glutathione disulfide (GSSH), ascorbate is oxidized via ascorbate peroxidase (APX) to form monodehydroascorbate (MDA) that dismutates into dehydroascorbate (DHA). Through the ascorbate-glutathione cycle, DHA can be reduced by DHA reductase reforming GSH and ascorbate [48]. Glutathione S-transferases (GSTs) also participate in the detoxification of reactive electrophillic compounds by catalysing their conjugation to GSH. Among GSTs, the DHA reductase class has a specialized function in reducing dehydroascorbate to ascorbic acid [49]. Finally, Sadenosylmethionine synthetase is an enzyme catalysing the formation of S-adenosylmethionine (SAM) from methionine and ATP. SAM serves as a precursor of nicotianamine, for which a role in metal ion homeostasis through chelation mechanisms has been reported [50,51], and as a key substrate of certain methylases for the regeneration of GSH [52,53]. Notably, among the aforementioned proteins, both APX and DHA reductase are known participants of the water-water cycle, also referred to as the Mehler reaction or Asada pathway [54], which plays a critical role in protecting the photosynthetic apparatus from photo-oxidative damage by dissipating excess light energy off the electron transport chain through the ascorbate peroxidase pathway. Besides APX and DHA reductase, ascorbate, glutathione and GSTs also have function in counteracting photoinhibition in the presence of excess excitation energy [54]. According to the down-accumulation of APX, DHA reductase, GST and SAM synthetase in plant shoots upon G. irregulare inoculation, we propose that the ascorbate-gluthatione cycle is less operative in mycorrhizal plants and that mycorrhization helps in reducing oxidative stress in photosynthetic organs. In favour of this hypothesis were the mycorrhization-induced increases in $\mathrm{CO}_{2}$ assimilation (s15, s16, s17), proteinpigment assembly (s1, s2, s3, s4, s5), which contribute in dissipating absorbed photon flux through the sufficient production of reducing equivalents [55]. Concomitantly, a significant decrease in the maximum quantum yields of nonphotochemical deexcitation and increase in the relative ETR were observed upon mycorrhization relative to control plants (Figure 4). Collectively, these data indicate that the mycorrhiza-responsive shoot proteome of $M$. truncatula is characterised by a reduction in antioxidant-related mechanisms and by an increase in photosynthesis-related processes that drive a decreased glycolytic flux.

Despite the model status of $M$. truncatula for legumes, untargeted approaches aiming at deciphering its molecular responses upon heavy metal exposure remain scarce [22] relative to those performed with its non-mycorrhizotroph counterpart Arabidopsis (reviewed in [24]). In the current work, by contrast to what observed upon mycorrhization in $M$. truncatula shoots (Figure 5A, Figure 6, column $\mathrm{Gi} / \mathrm{C}$ ), Cd triggered the down- and up-accumulation of VDAC1 (s11) and SAM synthetase (s20), respectively (Figure 6 , column $\mathrm{Cd} / \mathrm{C}$ ), a pattern that was ascribed to a plant defence response against $\mathrm{Cd}$-induced oxidative stress. In shoots of nonmycorrhizal plants, an increased accumulation of the pathogenesis-related (PR) protein $\beta$-glucanase (s6) was also observed upon $\mathrm{Cd}$ exposure (Figure 6, column $\mathrm{Cd} / \mathrm{C})$. Metal ions are not only well known to induce defence-related proteins as a result of cell-damaging actions, but also they share common signalling molecules with biotic stresses such as ethylene, salicylic acid and jasmonic acid [56]. Even though $\mathrm{Cd}$ is not a redoxactive metal per se [1], Cd can mediate the formation of ROS including superoxide anion and hydrogen peroxide by disrupting the balance between ROS generation and the antioxidant system activity $[6,57]$. In plants, $\mathrm{Cd}$ induced impairment of photosynthesis is considered as a one of the main causes of ROS production [58-60]. In M. truncatula, not only Cd reduced the Chl content in shoots of non-mycorrhizal plants (Figure 3), but also negatively affected both light-independent and dependent reactions of photosynthesis, as inferred from the decreased abundance of RuBisCO subunits, $\mathrm{RuBisCO}$ activases, and protein PsaD (Figure 5A, Figure 6: column $\mathrm{Cd} / \mathrm{C}$ ). Despite the major role attributed to the ascorbate-glutathione cycle in ROS alleviation, none of the proteins related to this process happened to belong to the Cd-responsive shoot proteome of $M$. truncatula (Figure 6, column $\mathrm{Cd} / \mathrm{C}$ ), indicating that this pathway might not be operative upon $\mathrm{Cd}$ exposure in our experimental conditions. In favour of this hypothesis was the down-accumulation of PsaD that was observed in the shoots of Cd-treated M. truncatula plants (Figure 6, column $\mathrm{Cd} / \mathrm{C}$ ). PsaD is a small extrinsic polypeptide of the PSI reaction centre complex that is required for native assembly of PSI reaction clusters [61]. A reduced electron flux due to PSI disassembly can generate direct photoreduction of oxygen, which leads to inactivation of ROS-scavenging enzymes and $\mathrm{CO}_{2}$ fixation $[54,61,62]$. PSI disassembly could further drive the destruction of PSII unit and thus a reduction in the density of active $\mathrm{RC}$ as presented in Figure 4. Overall, the metal-responsive shoot proteins currently identified in M. truncatula supports the view that an environmentally relevant supply of Cd impairs photosynthesis and generates an oxidative stress that cannot be efficiently counteracted (Figure 6, column $\mathrm{Cd} / \mathrm{C}$ ). 
The G. irregulare-responsive shoot proteome is qualitatively conserved but quantitatively modified upon Cd exposure

Following the analysis of the $M$. truncatula shoot proteome displayed in response to mycorrhization and $\mathrm{Cd}$ treatment (Figure 5C), 17 proteins showed a significant $(p<0.05)$ change in abundance relative to control plants, which was reproducible in the two biological experiments that were performed (Figure 6, column $\mathrm{CdGi} / \mathrm{C})$. Encompassing up-accumulation of proteins having function in the photosynthetic assimilation of $\mathrm{CO}_{2}$ /electron transport/structural proteins (s17, s1, s2, s3, s4), together with down-accumulation of glugoneogenesis/glycolysis-related enzymes (s7, s8, s9), the recorded modifications sustain, as discussed above, an increase photosynthetic activity (Figure 4) and the concomitant silencing of the glycolytic pathway in response to mycorrhization and $\mathrm{Cd}$ exposure. At the same time, cell defence-related mechanisms also were raised up, as mirrored by the increased abundance of PR protein (s6), APX (s22) and protein disulfide isomerase (PDI, s19), the latter facilitating protein folding via disulfide bond isomerization during de novo protein synthesis and the reassembly of molecules denatured by stress [63]. From the comparison of the $M$. truncatula shoot proteins that responded to the three different treatments (Figure 6, columns $\mathrm{Cd} / \mathrm{C}, \mathrm{Gi} / \mathrm{C}, \mathrm{CdGi} / \mathrm{C}$ ), the shoot proteome of Cd-treated mycorrhizal plants $(\mathrm{CdGi} / \mathrm{C})$ turned out to qualitatively resemble more that observed upon mycorrhization $(\mathrm{Gi} / \mathrm{C})$ than upon $\mathrm{Cd}$ supply $(\mathrm{Cd} / \mathrm{C})$ alone (Figure 6). Notably, out of the 17 proteins that changed in abundance in response to mycorrhization and $\mathrm{Cd}$ exposure (column CdGi/C), 13 spots (s7, s9, s8, s21, s1, s14, s12, s13, s17, s2, s4, s3, s23) displayed an accumulation pattern overlapping with mycorrhiza-related proteins (column $\mathrm{Gi} / \mathrm{C}$ ), whereas only one protein (PR protein s6) was reminiscent of the Cd-responsive shoot proteome (column $\mathrm{Cd} / \mathrm{C}$ ). Taken together, these observations substantiate the idea that the mycorrhizaresponsive proteome dominates that elicited by $\mathrm{Cd}$, as previously observed in metal-treated mycorrhizal roots [22].

The retrieved proteomic data also showed that part of AM symbiosis-related shoot proteins was quantitatively modified in presence of $\mathrm{Cd}$, as inferred from the analysis of the Cd-responsive mycorrhizal proteome (Figure 6, column CdGi/Gi). Besides the increased abundance of $\beta$-glucanase (s6), Cd was also found to trigger in shoot of mycorrhizal plants relative to those G. irregularecolonised but metal-free, the down-accumulation of cyclin (s10), VDAC1 (s11), RuBisCO small subunit (s5), PSI- and PSII-related proteins (s1, s2, s3, s4), coupled to the up-accumulation of gluconeogenesis/glycolytic enzymes (s7, s9), antioxidant-related proteins (SAM synthetase (s20), DHA reductase (s18), APX (s22)) and molecular chaperones (s12, s13, s19). From these observations, we propose that legume shoots of mycorrhizal plants escape $\mathrm{Cd}$ toxicity through the glycolysis-dependent mobilization of SAM synthetase, DHA reductase, APX and chaperones at the expense of the symbiotic sucrose sink. According to this model schematised in Figure 7, allocating less sucrose to the root inhabiting AM fungus would permit plants to retain more carbohydrates in their leaves to sustain repair mechanisms in response to foliar stress. Actually, when sucrose export is inhibited, sugars accumulate in the leaf [64] and down regulate photosynthesis to maintain homeostasis $[48,65]$, a process mirrored in the current study by the decreased abundance in $\mathrm{CO}_{2}$ assimilation-proteins (RuBisCO small subunit (s5), PSI- and PSII-related proteins (s1, s2, s3, s4) together with the reduced vitality indices and relative electron transport rate in Cd-treated mycorrhizal plants relative to those mycorrhizal but metal-free (Figure 4 and 6:column CdGi/Gi). Likewise, plants that exhibit a strong accumulation of hexoses in source leaves have been shown to display an increase defence status in their aboveground organs concomitant to an undersupply of carbohydrates to the roots and a reduced mycorrhization $[66,67]$. The assumption of a decreased sink demand is supported in our experimental conditions by the $50 \%$ lower development of the mycobiont in the roots of Cd-treated M. truncatula [22]. Consecutive to a minimised sucrose export to root sink tissues and the subsequent down-regulation of photosynthesis, chemical energy and carbon skeletons can be freed up as a source of metabolites to be used in a defence response through the glycolytic pathway via the activation of the enzyme PFK and the down-regulation of the energy-consuming gluconeogenesis process [48]. Namely, concomitant to the up-accumulation of fructose biphosphate aldolase and phosphoglycerate mutase (s7, s9), was an increased abundance in SAM synthetase, DHA reductase, APX, chaperones in Cd-treated mycorrhizal plants relative to those metal-free (Figure 6, column $\mathrm{CdGi} / \mathrm{Gi}$ ), which have function in counteracting $\mathrm{Cd}$-induced oxidative stress and/or in assisting folding during de novo protein synthesis. Overall, the proposed model implies a major role for the ascorbate-gluthatione cycle and molecular chaperones in Cd stress alleviation in shoots of mycorrhizal M. truncatula plants, but also presupposes that the mycorrhiza-induced sucrose sink and the concomitant increase in photosynthesis may be key actors in generating a carbon reserve to be mobilized in case of foliar stress (Figure 7). This idea is partly reminiscent of the "fuel for the fire" concept that illustrates plant leaf metabolism upon pathogen infection, in which carbohydrate increase is thought to be a metabolic signal that induces the expression of defence- 


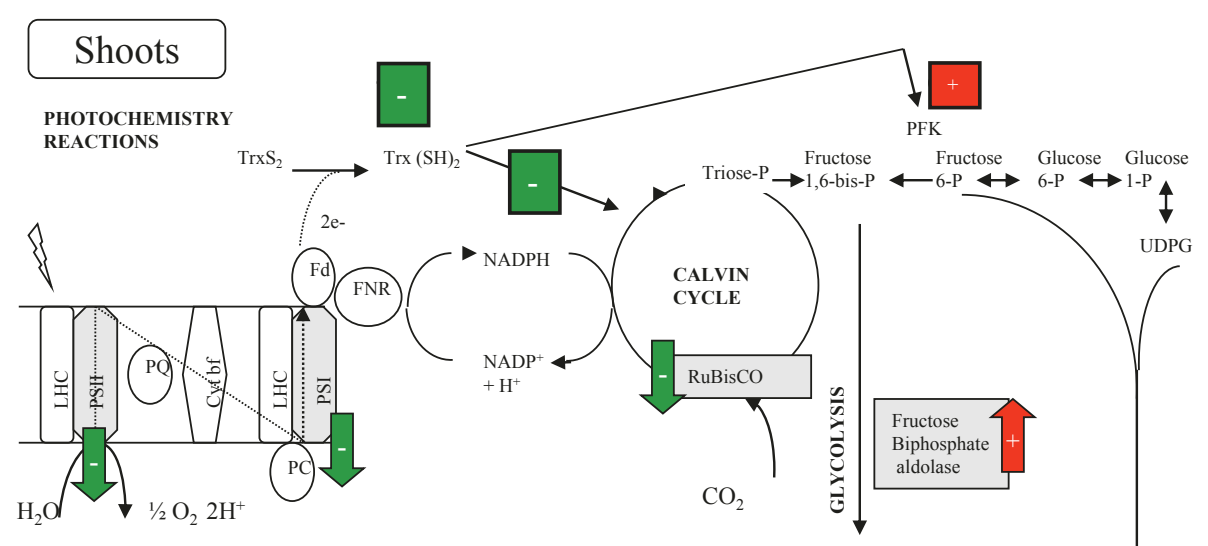

\section{REDOX HOMEOSTASIS/DETOXIFICATION}

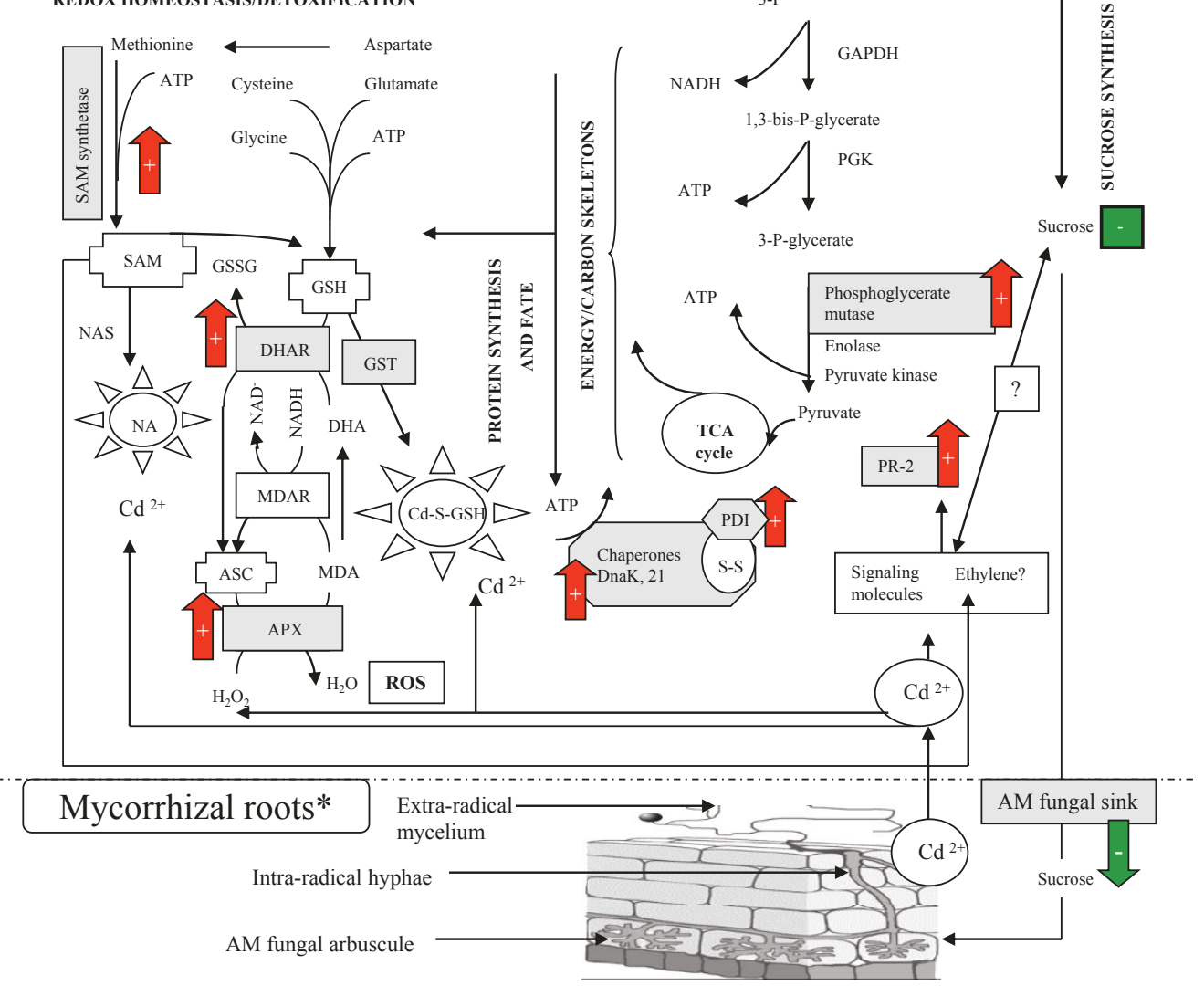

Figure 7 Schematic representation of the model proposed to explain cadmium stress alleviation in shoots of $M$. truncatula plants upon AM symbiosis. on the basis of the proteins and parameters identified in the current study as differentially accumulated in response to $G$. irregulare inoculation and/or metal treatment. Plant components identified in this work and explicit for this model are indicated in grey-shaded boxes. Red-shaded up- and green-shaded down-headed arrows indicate significant ( $n=3, p<0.05)$ increased and decreased component abundance in Cd-treated mycorrhizal plants relative to those only inoculated with G. irregulare, respectively. Green or red-shaded boxes indicate generally known mechanisms of regulation. Inferred metabolic pathways and intermediates are shown in non-shaded bold and non-bold letters, respectively. AM, arbuscular mycorrhizal; ASC, ascorbate; APX, ascorbate peroxidase; $\mathrm{Cd}^{2+}$, cadmium ion; DHA, dehydroascorbate; DHAR, dehydroascorbate reductase; Fd, ferredoxin; FNR, ferredoxin-NADP ${ }^{+}$reductase, GAPDH, glyceraldehyde-3-phosphate dehydrogenase; GSH, reduced glutathione; GSSH, glutathione disulfide; GST, glutathione S-transferase; LHC, light harvesting complex; MDA, monodehydroascorbate; MDAR, monodehydroascorbate reductase; NA, nicotianamine; NAS, nicotianamine synthase; P, phosphate; PC, plastocyanin; PDI, protein disulfide isomerase; PFK, phosphofructokinase; PGK, phosphoglyceraldehyde kinase; PQ, plastoquinone; PR-2, class 2 pathogenesis-related protein; PSI, photosystem I, PSII, photosystem II; ROS, reactive oxygen species; SAM, S-adenosylmethionine; TCA, tricarboxylic acid; Trs $\mathrm{S}_{2}$, thioredoxin disulfide; $\operatorname{Tr}(\mathrm{SH})_{2}$, reduced thioredoxin; UDPG, uridine diphosphoglucose; ; modified from [86]; $\mathbb{Q}$ indicates molecules having antioxidant properties; indicates molecules having metal chelation properties. 
related genes and repression of photosynthesis [68]. In this line of reasoning, sugar-sensing mechanisms are likely to play a critical role in regulating plant carbon partitioning and defence responses in mycorrhizal plants upon metal exposure.

\section{Conclusions}

Besides drawing a first picture of shoot proteome modifications upon AM symbiosis and/or heavy metal stress in legume plants, the current work argues for allocation plasticity as the main driving force for $\mathrm{Cd}$ extraction in aboveground tissues of $M$. truncatula, a conclusion matching with the view that high biomass producing plants take up a greater metal content than low biomass producing species [29]. Additionally, the retrieved proteomic data also give arguments in favour of the Audet and Charest's hypothesis [32] according to which metal toxicity escape in shoots of mycorrhizotrophic plants is not mediated through an intrinsic tolerance mechanism typical of $A$. thaliana, but is rather supported by the recruitment of antioxidant proteins at the expense of the symbiotic sucrose sink. Actually, the ascorbate-glutathione cycle and molecular chaperones recruited at the the proteome level upon $\mathrm{Cd}$ stress alleviation in shoots of mycorrhizal $M$. truncatula plants both belong to the generic cell signature elicited in response to abiotic stressors $[69,70]$. Notably, they were also suggested to participate in $\mathrm{Cd}$ detoxification in the model hyperaccumulator Thlaspi caerulescens [71], which led us to investigate whether commonalties may be shared upon heavy metal tolerance between mycorrhizal plants and T. caerulescens. Remarkably, out of the shoot proteins $T$. caerulescens whose abundance was modified upon $\mathrm{Zn} / \mathrm{Cd}$ exposures and/or metal-tolerant accessions were $\mathrm{CO}_{2}$ and electron transport-associated proteins, an ascorbate peroxidase, a dehydroascorbate reductase, a PDI, a $ß-1,3$-glucanase, an adenosine kinase having role in SAM regeneration and nicotianamine synthesis. These point out striking resemblances in the mechanisms candidate to heavy metal escape in those two plant systems, although hyperaccumulation was a term coined for plants able to tolerate and accumulate metals in their aboveground tissues in very high levels, e.g up to $10,000 \mathrm{ppm} \mathrm{Cd}$ in the shoot biomass [72], which is actually not the case for $M$. truncatula.

\section{Methods}

\section{Plant material}

For comparative purposes with the previously investigated root responses of $M$. truncatula during cadmium stress alleviation by arbuscular mycorrhiza, all the experiments reported in the current work were performed on the plant material described in [22]. It consisted of four batches of $M$. truncatula plants grown as follows: $M$. truncatula cv jemalong 5 were inoculated or not with the AM fungus Glomus irregulare DAOM 181602 (formerly known as Glomus intraradices N. C. Schenck \& G. S. Smith DAOM 181602; [73]) and half of the plants received a $\mathrm{Cd}\left(\mathrm{SO}_{4}\right)_{2}$ solution to obtain a final Cd concentration of $2 \mathrm{mg} \mathrm{kg}^{-1}$ substrate, which corresponds to the limit $\mathrm{Cd}$ values established for the European Community (http://www.ademe.fr/partenaires/ boues/pages/chap32.htm). Plants were grown for 3 weeks under controlled conditions ( $16 \mathrm{~h}$ photoperiod, $23^{\circ} \mathrm{C} / 18^{\circ} \mathrm{C}$ day $/$ night, $60 \%$ relative humidity, $220 \mu$ Einstein $\mathrm{m}^{-2} \cdot \mathrm{s}^{-1}$ photon flux density). Control and G. irregulare-inoculated plants either $\mathrm{Cd}$ treated or not were watered each day with demineralised water and once a week with a nitrogen-enriched nutrient solution [22]. The four treatments thus encompassed non inoculated plants grown without $\mathrm{Cd}(\mathrm{C}), \mathrm{G}$. irregulare-inoculated plants grown without $\mathrm{Cd}$ but inoculated with the $\mathrm{AM}$ fungus (Gi), non inoculated but $\mathrm{Cd}$-treated plants $(\mathrm{Cd})$, and G. irregulare-inoculated and Cd-treated plants (CdGi), which were available from two independent biological experiments. At time of harvest, shoot and roots were weighted; aerial parts of each treatment were further divided into three samples for cadmium quantification, morphological parameter and pigment content measurements, and protein extraction. Biomass measurements, estimation of mycorrhizal parameters of the root systems and Cd quantification were as described in [22].

\section{Metrics}

The tolerance indices for shoots of mycorrhizal and non-mycorrhizal $M$. truncatula plants were calculated according to [29] as the ratio of biomass ( $\mathrm{g}$ fresh weight) for plants grown in Cd-spiked substrate to plants grown in Cd-free substrate. Modified from the index of biomass partitioning [32], the contribution of shoots to plant biomass was measured as the ratio of shoot biomass ( $\mathrm{g}$ fresh weight) to that of whole plant. Root-toshoot translocation rates for $\mathrm{Cd}$ were calculated in mycorrhizal and non-mycorrhizal plants as the ratio of the $\mathrm{Cd}$ amount $(\mu \mathrm{g})$ in shoots to that in root $[27,30] . \mathrm{Cd}$ partitioning indices corresponded to the metal quantities $(\mu \mathrm{g})$ mobilized in plant organs [28].

\section{Shoot morphological analyses}

Shoot branch enumeration and leaf area measurement were performed for two biological experiments on three replicates, each consisting of six plants, after image capture by using the experimental design set up by [74] Briefly, for plant leaf area measurement, pictures were analysed using the software Visiolog 5.4 (Noesis, Les Ulis, France) in order to estimate the projected leaf area. The latter was determined by comparing pixel value for each plant to pixel value of a standard of known area. 


\section{Chlorophyll content measurement}

Pigments were extracted with $80 \%$ acetone and absorbance measured at 646 and $665 \mathrm{~nm}$. Chlorophyll $a$ (Chl $a)$ and chlorophyll $b(\mathrm{Chl} b)$ concentrations were calculated according to standard equations [75]. Chlorophyll content was determined for two biological experiments using three replicates per treatment, each consisting of five plants.

\section{Chlorophyll fluorescence measurement}

Chorophyll $a$ fluorescence induction kinetics were measured as previously described [76] on dark adapted (15 $\mathrm{min}$ ) attached leaves at room temperature. The activity of PSII was evaluated using the JIP-test based on the Chl $a$ Polyphasic Fluorecence Transient O-J-I-P [38]. Performance indices based on the JIP-test were calculated as described earlier [77]. The equations used to derive two types of parameters were as follows: (i): The photosynthetic efficiencies at the onset of illumination, i.e. the maximum quantum yield of PSII $\phi \mathrm{Po}=\mathrm{TR} 0 /$ $\mathrm{ABS}=\mathrm{Fv} / \mathrm{Fm}$ (where TR and ABS denote the trapped and absorbed excitation energy fluxes); the probability that an electron moves further than $\mathrm{Q}_{\mathrm{A}}$ (i.e. electron transfer (ET) $\psi \mathrm{o}=\mathrm{ET} 0 / \mathrm{TR} 0$; the quantum yield for electron transport $\phi \mathrm{Eo}=\mathrm{ET} 0 / \mathrm{ABS}$; the maximum quantum yield of nonphotochemical deexcitation $\phi \mathrm{Do}=\mathrm{DI} 0 /$ ABS, (ii): The vitality indices, i.e. the density of RCs per Chl $\mathrm{RC} / \mathrm{ABS}=\left(\mathrm{RC} / \mathrm{TR}_{0}\right)\left(\mathrm{TR}_{0} / \mathrm{ABS}\right)$, the conformation term for primary photochemistry $\phi \mathrm{Po} /(1-\phi \mathrm{Po})=\mathrm{TR} 0 /$ $\mathrm{DI}_{0}$, the conformation term for the thermal reactions (nonlight-depending reactions beyond $\left.\mathrm{Q}_{\mathrm{A}}{ }^{-}\right) \psi \mathrm{o} /(1-\psi \mathrm{o})=$ ET0/ $\left.\mathrm{dQ}_{\mathrm{A}}{ }^{-} / \mathrm{dt}_{0}\right)$, the performance indices for energy conservation from photons absorbed by PSII and per CS to the reduction of intersystem electron acceptors $\mathrm{PI}_{\mathrm{ABS}}$ and $\mathrm{PI}_{\mathrm{CS}}$, respectively and, the performance index for energy conservation from photons absorbed by PSII to the reduction of PSI end acceptors $\mathrm{PI}_{\mathrm{T} \text { to }}$. The data shown represent an average of 5 to 6 independent measurements per treatment and related statistical data are provided in additional file 2. Rapid response curves of photosynthesis versus irradiance were also measured. The quantum yield of PSII photochemistry (Y') was recorded on two different attached leaves for six plant replicates per treatment using 1-sec saturating pulses applied after every $20 \mathrm{sec}$ of illumination with photosynthetically active radiation (PAR) at intensities ranging from 0 to $800 \mu \mathrm{mol}$ photons $\mathrm{m}^{-2} \mathrm{sec}^{-1}$, increased stepwise (standardized automatic recording developed by Walz) [77]. The relative linear electron transport rate (ETR) was calculated by the equation ETR $=0.84 * \mathrm{R} *$ PAR " $Y$ ' [78]. It was assumed that $84 \%$ of the incident quanta were absorbed (factor 0.84), and that the fraction of the absorbed quanta distributed to PSII (factor R) was 0.6 for wt [79].

\section{Protein extraction}

Proteins were phenol-extracted from shoot tissues (1.5 g) as previously described [80]. Shoot were ground into liquid nitrogen and homogenised in $10 \mathrm{ml}$ of $0.5 \mathrm{M}$ Tris- $\mathrm{HCl}, \mathrm{pH} 7.5$, lysis buffer containing $0.7 \mathrm{M}$ sucrose, $50 \mathrm{mM}$ EDTA, $0.1 \mathrm{M} \mathrm{KCl}, 10 \mathrm{mM}$ thiourea, $2 \mathrm{mM}$ PMSF and $2 \%(\mathrm{v} / \mathrm{v}) \beta$-mercaptoethanol. One volume of Tris-buffered phenol was added and, after mixing for 30 min, the phenolic phase was separated by centrifugation and rinsed with another $10 \mathrm{ml}$ of lysis buffer. Proteins were precipitated overnight at $-20^{\circ} \mathrm{C}$ after adding 5 volumes of methanol containing $0.1 \mathrm{M}$ ammonium acetate. The pellet recovered by centrifugation was rinsed with cold methanol and acetone, dried under nitrogen gas and resuspended into $200 \mu \mathrm{l}$ of $9 \mathrm{M}$ urea, $4 \% \mathrm{w} / \mathrm{v}$ CHAPS, $0.5 \% \mathrm{v} / \mathrm{v}$ Triton X-100, $100 \mathrm{mM}$ DTT and $2 \%$ v/v IPG buffer pH 3-10 (Amersham Biosciences). Lipids and nucleic acids were removed by a $30 \mathrm{~min}$ ultracentrifugation step at 170,000 $g$ (Airfuge, Beckman Coulter). The protein content of the supernatant was quantified by the modified Bradford method as described in Ramagli and Rodriguez [81] using BSA as a standard. In the two independent biological experiments that were performed, proteins were extracted for each treatment from three shoot samples, each consisting of six plants.

\section{2-DE analysis}

2-DE was performed as described previously [22]. Precast $18 \mathrm{~cm}$ nonlinear pH 3-10 IPG strips (Amersham Biosciences) were rehydrated overnight with $600 \mu \mathrm{g}$ of shoot proteins in $350 \mu \mathrm{l}$ of $8 \mathrm{M}$ urea, $2 \% \mathrm{v} / \mathrm{v}$ CHAPS, $20 \mathrm{mM}$ DTT, 2\% v/v IPG buffer $\mathrm{pH}$ 3-10 and bromophenol blue. Isoelectofocusing was carried out for 71 $\mathrm{kVh}$ using a gradually increasing voltage at $20^{\circ} \mathrm{C}$. Strips were then either stored at $-80^{\circ} \mathrm{C}$ or immediately equilibrated. The second dimension was performed onto homemade $12 \%$ pH 8.8 SDS-polyacrylamide gels (Hoefer DALT, Amersham Biosciences). Electrophoresis was run at $10^{\circ} \mathrm{C}$ for $1 \mathrm{~h}$ at $35 \mathrm{~V}$, and then at $80 \mathrm{~V}$ until the dye front reached the bottom of the gels. For each treatment, 2-DE was performed for three different shoot protein samples, each consisting of six pooled shoot systems, and two independent biological experiments were analysed. The 2-DE gels were stained with Coomassie Brilliant Blue according to [82].

\section{Image analysis}

Stained gels were scanned using the Odyssey Infrared Imaging System (LI-COR Biosciences, GmbH, Germany) at $700 \mathrm{~nm}$ with a resolution of $169 \mu \mathrm{m}$. Image analyses were carried out with the Progenesis SameSpots version 2.0 software (nonlinear dynamics) according to manufacturer's instructions. Quantification was performed independently for two biological experiments, 
corresponding to a total number of 24 gels (4 treatments $\times 3$ independent analytical gels $\times 2$ biological replicates). For each treatment, only protein spots showing significant abundance modification in the two independent biological experiments were considered as differentially accumulated.

\section{In gel digestion and MALDI-TOF analysis}

Following extensive gel washing with water, spots of interest were manually excised with tips, dried and stored at room temperature before mass spectrometry analyses. Gel plugs were washed until de-staining in 100 $\mu \mathrm{l}$ of a $50 \%$ acetonitrile/ $50 \mathrm{mM}$ hydrogenocarbonate $\mathrm{pH}$ 8 solution and then dried under vacuum. After rehydratation in $10 \mu \mathrm{l}$ of $50 \mathrm{mM}$ ammonium hydrogenocarbonate $\mathrm{pH} 8$ containing $0.1 \mu \mathrm{g}$ of porcine trypsin (Promega), samples were incubated overnight (16-18 h) at $37^{\circ} \mathrm{C}$. Peptide masses from digested proteins were obtained using a MALDI-TOF-MS equipped with a $\mathrm{N}_{2}$ laser (337 nm, $20 \mathrm{~Hz}$, 3ns impulsion) (Voyager DE super STR, Applied Biosystems). Samples were irradiated in a matrix ( $\alpha$-cyano-4-hydroxycinnamic acid 4 $\mathrm{mg} / \mathrm{ml}$ ) and spectra were acquired in reflectron mode within a 700 to $3500 \mathrm{Da}$ mass range and a $130 \mathrm{~ns}$ delay extraction time. Internal calibration was performed using trypsin peptide masses within a 500 to $5000 \mathrm{Da}$ range.

PMF search was performed as described in [83] on SwissProt and on the two clustered EST M. truncatula database available online (http://medicago.toulouse. inra.fr/Mt/EST/DOC/MtB.html) according to [84]. The first one, named MtC, contained 6350 clusters defined from three root EST libraries (24347 ESTs) of a Genoscope project (http://www.cns.fr/). The clustering process has been previously described in [85]. The second one, named MtD, was obtained using the same process on the M. truncatula ESTs (approximately 180000 ESTs) available at the Institute for Genomic Research (http://compbio.dfci.harvard.edu/tgi/). It contained 21400 clusters defined from EST libraries corresponding to different $M$. truncatula tissues. Search for PMF matches was performed in the clustered EST M. truncatula databases using the protein prospector software (http://prospector.ucsf.edu/prospector/mshome.htm) and in SwissProt using the profound software (http:// prowl.rockefeller.edu/prowl-cgi/profound.exe). For peptide matching, a minimum of four peptides matches and $15 \%$ sequence coverage, a maximum of one miscleavage, and peptide modifications by carboxyamidomethylcysteine, methionine sulfoxide, and pyroglutamic acid or acetylated $\mathrm{N}$-terminal residue, were accepted. The maximum tolerance for peptide mass matching was limited to $20 \mathrm{ppm}$.

\section{Data analyses}

Means were compared using analysis of variance (ANOVA, $p<0.05$ ) using STATISTICA (version 7.1

StatSoft, Inc., 2005, FR; http://www.statsoft.fr). When necessary, data were subjected to arcsin transformation before comparison. For image analysis quantification, homogeneity of the variance was tested and data were subjected to square root transformation when the variances among treatments were not homogeneous. The Tukey's test was used as a post hoc test when ANOVA showed significance. The groups of proteins that responded to $\mathrm{Cd}$ and/or $\mathrm{AM}$ fungal colonisation relative to non-treated plants were further compared using GENESIS clustering (version 1. 7. 2; Graz University of Technology; Institute for Genomics and Bioinformatics). For that purpose, quantitative variations in protein abundance between treatments were represented by Log2 ratios of normalized volume obtained by SameSpots image analysis.

\section{Additional material}

\begin{abstract}
Additional file 1: Impact of cadmium (Cd) and/or G. irregulare inoculation (Gi) on biomass ( $\mathrm{g}$ fresh weight) of 3-wk old $M$. truncatula plants relative to those non-treated (C), as presented in figure 2. For two independent biological experiments (Exp), histograms represent means of three replicates (means $\pm S D, n=3$ ). Means marked with different letters indicate significant difference at $p<0.05$.

Additional file 2: $p$ values $(n \geq 5)$ relative to the parameters of the OJIP-test and relative electron transport rate presented in figure 4 The values below 0.05 are indicated in bold.

Additional file 3: Characteristics of the proteins identified in Medicago truncatula shoots, whose accumulation was modified in response to Glomus irregulare plant inoculation and/or cadmium supply relative to non-treated plants. This table includes the annotation, accession number, peptide sequences, percent coverage of the complete sequence, experimental and theoretical Mw and pl of the 23 proteins detected differentially accumulated in this study $(\mathrm{n}=3, p<$ 0.05)

Additional file 4: Mass spectrometry data supplied in the mzML format.
\end{abstract}

\section{Acknowledgements}

The authors would like to thank H-N Truong and I Negrel for their very helpful support.

\section{Author details}

1UMR INRA 1088/CNRS 5184/UB. Plante-Microbe-Environnement. INRA-CMSE. BP 86510. 21065 Dijon Cedex, France. ²Département des Sciences Biologiques, Faculté des Sciences de Tunis, Campus universitaire, 1060 Tunis, Tunisia. ${ }^{3}$ Microorganismes, Metaux et Toxicité, Institut National des Sciences et Techniques de la Mer, Conservatoire National des Arts et Métiers, BP 324 50103 Cherbourg-Octeville Cedex, France. ${ }^{4}$ Unité de Biochimie Bactérienne, PAPPSO, batiment 526, Domaine de Vilvert 78352, Jouy en Josas Cedex, France.

Authors' contributions

AA participated in experimental design, conducted the bulk of experimental work, performed 2D-electrophoresis and statistical analyses. GR participated 
in data analysis and drafted the manuscript. FR participated in the experimental work. BS and MB performed chlorophyll fluorescence measurements, help to draft the manuscript and were involved in revising the manuscript critically. CH performed mass spectrometry analyses. VGP, EDG and SAS conceived, designed and supervised the study and were involved in revising the manuscript critically. All authors have read and approved the final manuscript.

Received: 2 November 2010 Accepted: 5 May 2011 Published: 5 May 2011

\section{References}

1. Schützendübel A, Polle A: Plant responses to abiotic stresses: heavy metal-induced oxidative stress and protection by mycorrhization. J Exp Bot 2002, 53:1351-1365.

2. Hernández LE, Cooke TC: Modification of the root plasma membrane lipid composition of cadmium-treated Pisum sativum. J Exp Bot 1997, 48:1375-1381.

3. Das P, Samantaray S, Rout GR: Studies on cadmium toxicity in plants: a review. Environ Pollut 1997, 98:29-36.

4. Clemens S: Toxic metal accumulation, responses to exposure and mechanisms of tolerance in plants. Biochimie 2006, 88:1707-1719.

5. Sandalio LM, Dalurzo HC, Gómez M, Romero-Puertas MC, del Río LA: Cadmium-induced changes in the growth and oxidative metabolism of pea plants. J Exp Bot 2002, 52:2015-2026.

6. Bertrand $M$, Poirier l: Photosynthetic organisms and excess of metals. Photosynthetica 2005, 43:345-353.

7. Hall JL: Cellular mechanisms for heavy metal detoxification and tolerance. J Exp Bot 2002, 53:1-11.

8. Gamalero E, Lingua G, Berta G, Glick BR: Beneficial role of plant growth promoting bacteria and arbuscular mycorrhizal fungi on plant responses to heavy metal stress. Can J Microbiol 2009, 55:501-514.

9. Farinati S, DalCorso G, Bona E, Corbella M, Lampis S, Cecconi D, Polati R, Berta G, Vallini G, Furini A: Proteomic analysis of Arabidopsis halleri shoots in response to the heavy metals cadmium and zinc and rhizosphere microorganisms. Proteomics 2009, 9:4837-4850.

10. Leyval C, Joner EJ, del Val C, Haselwandter K: Potential of arbuscular mycorrhizal fungi for bioremediation. In Mycorrhizal technology in agriculture. Edited by: Gianinazzi S, Schüepp H, Barea JM, Haselwandter K. Basel: Birkhäuser Verlag; 2002:175-186.

11. Göhre V, Paszkowski U: Contribution of the arbuscular mycorrhizal symbiosis to heavy metal phytoremediation. Planta 2006, 223:1115-1122.

12. Smith SE, Read DJ: Mycorrhizal Symbiosis London: Academic Press; 1997.

13. Harrison MJ: Molecular and cellular aspects of the arbuscular mycorrhizal symbiosis. Annu Rev Plant Physiol Plant Mol Biol 1999, 50:361-389.

14. Bücking $H$, Shachar-Hill $Y$ : Phosphate uptake, transport and transfer by the arbuscular mycorrhizal fungus Glomus intraradices is stimulated by increased carbohydrate availability. New Phytol 2005, 165:899-911.

15. Davies FT Jr, Puryear JD, Newton RJ, Egilla JN, Saraiva Grossi JA: Mycorrhizal fungi enhance accumulation of chromium in sunflower (Helianthus annuus). J Plant Physiol 2001, 158:777-786.

16. Joner EJ, Briones R, Leyval C: Metal-binding capacity of arbuscular mycorrhizal mycelium. Plant Soil 2000, 226:227-234.

17. Janoušková M, Pavliková D, Vosátka M: Potential contribution of arbuscular mycorrhiza to cadmium immobilisation in soil. Chemosphere 2006, 65:1959-1965.

18. González-Guerrero M, Benabdellah K, Valderas A, Azcón-Aguilar C, Ferrol N: Gint $A B C 1$ encodes a putative $A B C$ transprter of the MRP subfamily induced by $\mathrm{Cu}, \mathrm{Cd}$, and oxidative stress in Glomus intraradices. Mycorrhiza 2010, 20:137-146.

19. Hildebrandt $U$, Regvar $M$, Bothe $H$ : Arbuscular mycorrhiza and heavy metal tolerance. Phytochem 2007, 68:139-146.

20. Ouziad F, Hilderbrandt U, Schmelzer E, Bothe H: Differential gene expression in arbuscular mycorrhizal-colonized tomato grown under heavy metal stress. J Plant Physiol 2005, 162:634-649.

21. Rivera-Becerril F, van Tuinen D, Martin-Laurent F, Metwally A, Dietz KJ, Gianinazzi S, Gianinazzi-Pearson V: Molecular changes in Pisum sativum L. roots during arbuscular mycorrhiza buffering of cadmium stress. Mycorrhiza 2005, 16:51-60.

22. Aloui A, Recorbet G, Gollotte A, Robert F, Valot B, Gianinazzi-Pearson V, Aschi-Smiti S, Dumas-Gaudot E: On the mechanisms of cadmium stress alleviation in Medicago truncatula by arbuscular mycorrhizal symbiosis: a root proteomic study. Proteomics 2009, 9:420-433.

23. Rivera-Becerril F, Calantzis C, Turnau K, Caussanel JP, Belimov AA, Gianinazzi S, Strasser RJ, Gianinazzi-Pearson V: Cadmium accumulation and buffering of cadmium-induced stress by arbuscular mycorrhiza in three Pisum sativum L. genotypes. J Exp Bot 2002, 53:1177-85.

24. Ahsan N, Renaut J, Komatsu S: Recent developments in the application of proteomics to the analysis of plant responses to heavy metals. Proteomics 2009, 9:2602-21.

25. Salt DE, Smith RD, Raskin I: Phytoremediation. Annu Rev Plant Physiol Plant Mol Biol 1998, 49:643-668.

26. Shi G, Cai Q: Cadmium tolerance and accumulation in eight potential energy crops. Biotechnol Adv 2009, 27:555-561.

27. Wu F, Yang W, Zhang J, Zhou L: Cadmium accumulation and growth responses of a poplar (Populus deltoids $\times$ Populus nigra) in cadmium contaminated purple soil and alluvial soil. J Hazard Mater 2010, 177:268-273.

28. Redon PO, Béguiristain T, Leyval C: Influence of Glomus intraradices on Cd partitioning in a pot experiment with Medicago truncatula in four contaminated soils. Soil Biol Biochem 2008, 40:2710-2712.

29. Audet $P$, Chatest C: Heavy metal phytoremediation from a metaanalytical perspective. Environ Pollut 2007, 147:231-237.

30. Wang J, Fang W, Yang Z, Yuan J, Zhu Y, Yu H: Inter- and intraspecific variations of cadmium accumulation of 13 leafly vegetable species in a grennhouse experiment. J Agric Food Chem 2007, 55:9118-9123.

31. de Andrade SA, da Silveira AP, Jorge RA, de Abreu MF: Cadmium accumulation in sunflower plants influenced by arbuscular mycorrhiza. Int J Phytoremediation 2008, 10:1-13.

32. Audet $P$, Charest $C$ : Allocation plasticity and plant-metal partitioning: Meta-analytical perspectives in phytoremediation. Environ Pollut 2008, 156:290-296.

33. Visioli G, Marmiroli M, Marmiroli N: Two-dimensional liquid chromatography technique coupled with mass spectrometry analysis to compare the proteomic response to cadmium stress in plants. J Biomed Biotechnol 2010, 10, Article ID 567510.

34. Wright DP, Scholes JD, Read DJ: Effects of VA mycorrhizal colonisation on photosynthesis and biomass production of Trifolium repens, L. Plant Cell Environ 1998, 21:209-216.

35. Stobart A, Griffiths W, Ameen-Bukhari I, Sherwood R: The effect of $\mathrm{Cd}^{2+}$ on the biosynthesis of chlorophyll in leaves of barley. Physiol Plant 1985, 63:293-298.

36. Schoefs B: Protochlorophyllide reduction - what is new in 2005 ? Photosynthetica 2005, 43:329-343.

37. Strasser RJ, Srivastava A, Tsimilli-Michael M: Analysis of the chlorophyll a fluorescence transient. In Advances in Photosynthesis and Respiration Series: Chlorophyll a Fluorescence: a Signature of Photosynthesis. Volume 19. Edited by: Papageorgiou G, Govindjee. Rotterdam: Kluwer; 2004:321-362.

38. Rohacek K, Soukupova J, Bartak M: Chlorophyll fluorescence: a wonderful tool to study plant physiology and plant stress. In Plant Cell Compartments-Selected Topics. Edited by: Schoefs B. Kerala: Research Signpost; 2008:41-104

39. Pietrini $F$, lannelli MA, Pasqualini S, Massacci A: Interaction of cadmium with glutathione and photosynthesis in developing leaves and chloroplasts of Phragmites australis (Cav.) Trin. Ex Steudel. Plant Physiol 2003, 133:829-837.

40. Liu JY, Maldonado-Mendoza I, Lopez-Meyer M, Cheung F, Town CD, Harrison MJ: Arbuscular mycorrhizal symbiosis is accompanied by local and systemic alterations in gene expression and an increase in disease resistance in the shoots. Plant J 2007, 50:529-544.

41. Bago B, Pfeffer PE, Shachar-Hill Y: Carbon metabolism and transport in arbuscular mycorrhizas. Plant Physiol 2000, 124:949-958.

42. Tester M, Smith F, Smith S: Phosphate inflow into Trifolium subterraneum L.: Effects of photon irradiance and mycorrhizal infection. Soil Biol Biochem 1985, 17:807-810.

43. Frydman J: Folding of newly translated proteins in vivo: the role of molecular chaperones. Annu Rev Biochem 2001, 70:603-647.

44. Buchanan BB: Role of light in the regulation of chloroplast enzymes. Annu Rev Plant Physiol 1980, 31:341-374.

45. Stitt M: Fructose-2,6-biphosphate as a regulatory molecule in plants. Annu Rev Plant Physiol Plant Mol Biol 1990, 41:153-185. 
46. Qin G, Meng X, Wang Q, Tian S: Oxidative damage of mitochondrial proteins contributes to fruit senescence: a redox proteomics analysis. $J$ Proteome Res 2009, 8:2449-2462.

47. Karachitos A, Galganska H, Wojtkowxka M, Budzinska M, Stobiena O, Bartosz G, Kmita H: Cu,Zn-superoxide dismutase is necessary for proper function of VDAC in Saccharomyces cerevisiae cells. FEBS Lett 2009, 22:449-455.

48. Apel $\mathrm{K}$, Hirt $\mathrm{H}$ : Reactive oxygen species: metabolism, oxidative stress, and signal transduction. Annu Rev Plant Biol 2004, 55:373-399.

49. Frova C: The plant glutathione transferase gene family: Genomic structure, functions, expression and evolution. Physiol Plant 2003, 119:469-479

50. Stephan UW, Cholz G: Nicotianamine: mediator of transport of iron and heavy metals in the phloem? Physiol Plant 1993, 88:522-529.

51. Weber H, Harada E, Vess C, Roepenack-Lahaye E, Clemens S: Comparative microarray analysis of Arabidopsis thaliana and Arabidopsis halleri roots identifies nicotianamine synthase, a ZIP transporter and other genes as potential metal hyperaccumulation factors. Plant J 2004, 37:269-281

52. Roth U, von Roepenack-Lahaye $\mathrm{E}$, Clemens S: Proteome changes in Arabidopsis thaliana roots upon exposure to $\mathrm{Cd}^{2+}$. J Exp Bot 2006 57:4003-4013.

53. Sarry JE, Kuhn L, Ducruix $C$, Lafaye A, Junot $C$, Hugouvieux $V$, Jourdain $A$, Bastien O, Fievet JB, Vailhen D, Amekraz B, Moulin C, Ezan E, Garin J, Bourguignon J: The early responses of Arabidopsis thaliana cells to cadmium exposure explored by protein and metabolite profiling analyses. Proteomics 2006, 6:2180-2198.

54. Asada K: The water-water cycle in chloroplasts: scavenging of active oxygens and dissipation of excess photons. Annu Rev Plant Physiol Plant Mol Biol 1999, 50:601-639.

55. Li Q, Chen LS, Jiang HX, Tang N, Yang LT, Lin ZH, Li Y, Yang GH: Effects of manganese-excess on $\mathrm{CO}_{2}$ assimilation, ribulose-1,5-biphosphate carboxylase/oxygenase, carbohydrates and photosynthetic electron transport of leaves, and antioxidant systems of leaves and roots in Citrus grandis seedlings. BMC Plant Biol 2010, 10:42.

56. Poschenrieder C, Tolrà R, Barceló J: Can metals defend plants against biotic stress? Trends Plant Sci 2006, 11:288-295.

57. Zhang F, Zhang H, Wang G, Xu L, Shen Z: Cadmium-induced accumulation of hydrogen peroxide in the leaf apoplast of Phaseolus aureus and Vicia sativa and the roles of different antioxidant enzymes. J Hazard Mater 2009, 168:76-84

58. Romero-Puertas MC, Rodríguez-Serrano M, Corpas FJ, Gómez M, Del Rio LA, Sandalio LM: Cadmium-induced subcellular accumulation of $\mathrm{O}_{2}{ }^{-}$and $\mathrm{H}_{2} \mathrm{O}_{2}$ in pea leaves. Plant Cell Environ 2004, 27:1122-1134.

59. Benavides MP, Gallego SM, Tomaro ML: Cadmium toxicity in plants. Brz J Plant Physiol 2005, 17:21-34.

60. Martinez Dominguez D, Cordoba Garcia F, Canalejo Raya A, Torronteres Santiago R: Cadmium-induced oxidative stress and the response of the antioxidative defense system in Spartina densiflora. Physiol Plant 2010, 139:289-302.

61. Xia Z, Broadhurst RW, Laue ED, Bryant DA, Golbeck JH, Bendall DS: Structure and properties in solution of PsaD, an extrinsic polypeptide of photosystem I. Eur J Biochem 1998, 255:309-316.

62. Fagioni M, d'Aminci GM, Timperio AM, Zolla L: Proteomic analysis of multiprotein complexes in the thylakoid membrane upon cadmium treatment. J Proteome Res 2009, 8:310-326.

63. Noiva R: Protein disulfide isomerase: the multifunctional redox chaperone of the endoplasmic reticulum. Semin Cell Dev Biol 1999, 10:481-493.

64. von Schaewen A, Stitt M, Schmidt R, Willmitzer L: Expression of a yeastderived invertase in the cell wall of tobacco and Arabidopsis plants leads to accumulation of carbohydrate, inhibition of photosynthesis and strongly influences growth and phenotype of transgenic tobacco plants. EMBO J 1990, 9:3033-3044.

65. Gupta AK, Kaur N: Sugar signalling and gene expression in relation to carbohydrate metabolism under abiotic stresses in plants. J Biosci 2005, 30:761-776.

66. Schaarschmidt S, Kopta J, Ludwig-Müller J, Hause B: Regulation of arbuscular mycorrhization by apoplastic invertases: enhanced invertase activity in the leaf apoplast affects the symbiotic interaction. Plant J 2007, 51:390-405.

67. Schaarsmidt S, Hause B: Apoplastic invertases: multi-faced players in the arbuscular mycorrhization. Plant Signal Behav 2008, 3:317-319.
68. Bolton MD: Primary metabolism and plant defense-Fuel for the fire. Mol Plant-Microbe Interact 2009, 22:487-497.

69. Leshem YY, Kuiper PJC, Erdei L, Lurie S, Perl-Treves R: Do Selye's mammalian GAS concept and co-stress response exist in plants? Ann N Y Acad Sci 1998, 851:199-208

70. Durand TC, Sergeant K, Planchon S, Carpin S, Label P, Morabito D, Hausman JF, Renaut J: Acute metal stress in Populus tremula $\times$ P. alba (717-1B4 genotype): leaf and cambial proteome changes induced by cadmium $^{2+}$. Proteomics 2010, 10:349-368.

71. Tuomainen MH, Nunan N, Lehesranta SJ, Tervahauta Al, Hassinen VH, Schat H, Koistinen KM, Auriola S, Mcnicol J, Kärenlampi SO: Multivariate analysis of protein profiles of metal hyperaccumulator Thlaspi caerulescens accessions. Proteomics 2006, 6:3696-706.

72. Milner M, Kochian LV: Investigating heavy-metal hyperaccumulation using Thlaspi caerulescens as a model system. Ann Bot 2008, 102:3-13.

73. Stockinger H, Walker C, Schüßler A: "Glomus intraradices DAOM197198", a model fungus in arbuscular mycorrhiza reaserach, is not Glomus intraradices. New Phyto 2009, 183:1176-1187.

74. Moreau D, Schneider C, Huguet T, Salon C, Munier-Jolain N: Can differences of nitrogen nutrition level among Medicago truncatula genotypes be assessed non destructively? Probing with a recombinant inbred lines population. Plant Signal Behav 2009, 4:30-32.

75. Porra RJ: The chequered history of the development and use of simultaneous equations for the accurate determination of chlorophylls a and b. Photosynth Res 2002, 73:149-156.

76. Yin L, Lundin B, Bertrand M, Nurmi M, Solymosi K, Kangasjarvi S, Aro EM, Schoefs B, Spetea C: Role of thylakoid ATP/ADP carrier in photoinhibition and photoprotection of photosystem II in Arabidopsis. Plant Physiol 2010, 153:666-677.

77. Lundin B, Hansson M, Schoefs B, Vener AV, Spetea C: The Arabidopsis $\mathrm{PsbO} 2$ protein regulates dephosphorylation and turnover of the photosystem II reaction centre D1 protein. Plant J 2007, 49:528-539.

78. Genti BE, Briantais JM, Baker NR: The relationship between the quantum yield of photosynthetic electron transport and quenching of chlorophyll fluorescence. Biochim Biophys Acta 1998, 990:87-92.

79. Suorsa M, Sirpiö S, Allahverdiyeva Y, Paakkarinen V, Mamedov F, Styring S, Aro EMJ: PsbR, a missing link in the assembly of the oxygen-evolving complex of plant photosystem II. Biol Chem 2006, 281:145-50.

80. Bestel-Corre G, Dumas-Gaudot E, Poinsot V, Dieu M, Dierick JF, van Tuinen D, Remacle J, Gianinazzi-Pearson V, Gianinazzi S: Proteome analysis and identification of symbiosis-related proteins from Medicago truncatula Gaertn. by two-dimensional electrophoresis and mass spectrometry. Electrophoresis 2002, 23:122-137.

81. Ramagli LS, Rodriguez LW: Quantification of microgram amounts of protein in two-dimensional polyacrylamide gel electrophoresis sample buffer. Electrophoresis 1985, 6:559-563.

82. Mathesius U, Keijzers G, Natera SHA, Weinman JJ, Djordjevic MA, Rolfe BG: Establishment of a root proteome reference map for the model legume Medicago truncatula using the expressed sequence tag database for peptide mass fingerprinting. Proteomics 2001, 1:1424-1440

83. Amiour N, Recorbet G, Robert F, Gianinazzi S, Dumas-Gaudot E: Mutations in DMI3 and SUNN modify the appressorium-responsive root proteome in arbuscular mycorrhiza. Mol Plant-Microbe Interact 19:988-997.

84. Valot B, Gianinazzi S, Dumas-Gaudot E: Sub-cellular proteomic analysis of a Medicago truncatula root microsomal fraction. Phytochem 2004, 65:1721-1732.

85. Journet EP, van Tuinen D, Gouzy J, Crespeau H, Carreau V, Farmer MJ, Niebel A, Schiex T, Jaillon O, Chatagnier O, Godiard L, Micheli F, Kahn D, Gianinazzi-Pearson V, Gamas P: Exploring root symbiotic programs in the model legume Medicago truncatula using EST analysis. Nucl Acids Res 2002, 30:5579-5592.

86. Recorbet G, Valot B, Dumas-Gaudot E: Plasma membrane proteins in arbuscular mycorrhiza. In Plant Cell Compartments-Selected Topics. Edited by: Schoefs B. Kerala: Research Signpost; 2008:367-384.

doi:10.1186/1471-2229-11-75

Cite this article as: Aloui et al:: Arbuscular mycorrhizal symbiosis elicits shoot proteome changes that are modified during cadmium stress alleviation in Medicago truncatula. BMC Plant Biology 2011 11:75. 